\title{
Climate change in Africa: costs of mitigating heat stress
}

\author{
Ben Parkes ${ }^{1,2}$ (D) . Jennifer Cronin ${ }^{3} \cdot$ Olivier Dessens $^{3} \cdot$ Benjamin Sultan $^{4}$
}

Received: 8 March 2017 / Accepted: 1 March 2019 / Published online: 6 April 2019

(C) The Author(s) 2019

\begin{abstract}
We applied two metrics, apparent temperature and humidex, to calculate heat stress in both present and future climates. We use an ensemble of CORDEX-Africa simulations to estimate heat stress during a baseline period and at two specific warming levels, 2 and $4{ }^{\circ} \mathrm{C}$ above pre-industrial. The increase in temperatures and changes to the precipitation distribution under climate change are projected to increase the intensity of heat stress events in Sahelian Africa and introduce new heat stress events in Northern and Central Africa. As the intensity of heat stress increases, it is expected that the use of energy-intensive cooling will increase. The energy system, therefore, will need to be able to supply more energy to power fans or air conditioning units. The cooling demand to turn a heat stress event into a nonheat stress event is computed. This value is then weighted by the population to find the total cooling required to prevent heat stress across the continent. Country-level results indicate that the greatest increases in cooling demand will occur in countries with densely populated regions, most notably Nigeria. Supplying this additional cooling demand will present the greatest challenge to less developed countries like Somalia. We find the least-cost future energy system that meets the projected increase in demand and derive the increase in energy system costs with the TIAM-UCL model. The total increase in energy costs to prevent heat stress is found to be $\$ 51$ bn by 2035 and $\$ 487$ bn by 2076 .
\end{abstract}

Electronic supplementary material The online version of this article

(https://doi.org/10.1007/s10584-019-02405-w) contains supplementary material, which is available to authorized users.

Ben Parkes

ben.parkes@manchester.ac.uk

1 Sorbonne Universités, (UPMC, Univ. Paris 06)-CNRS-IRD-MNHN LOCEAN/IPSL, 4 Place Jussieu, F-75005, Paris, France

2 Present address: School of Mechanical, Aerospace and Civil Engineering, University of Manchester, Manchester, M13 9PL, UK

3 Energy Institute, University College London, London, WC1H 0NN, UK

4 ESPACE-DEV, Univ Montpellier, IRD, Univ Guyane, Univ Réunion, Univ Antilles, Univ Avignon, Montpellier, France 


\section{Introduction}

Heat stress is the inability of a body to cool sufficiently to maintain a stable internal temperature. Methods of mitigating heat stress include evaporative cooling, seeking shade, utilising additional space cooling or altering schedules to allow high intensity work in cooler temperatures (Suzuki-Parker and Kusaka 2016). An increase in the number of heat-related deaths as a result of climate change has been observed (Field et al. 2014). With further increasing temperatures, the number of heat-related deaths is likely to increase (Dunne et al. 2013).

Heat stress is affected by the ambient conditions and vulnerability or personal perception. There are several different heat stress metrics (Buzan et al. 2015), which are dependent on a number of variables including temperature, relative humidity, wind speed and radiation. Tropical regions with high temperatures and humidity are more vulnerable to heat stress than temperate or polar regions (Zhao et al. 2015). Coastal cities are particularly susceptible to changes in heat stress as evaporation from the sea increases the water vapour pressure which is a key component of heat stress (Diffenbaugh et al. 2007).

Increases in heat stress reduce a person's ability to work; manual labour is increasingly difficult as the body cannot disperse heat quickly enough (Kjellstrom et al. 2009). In environments where body heat is not the limiting factor, it is still possible for heat to have an effect, as hotter environments require more cooling for comfort and food requires more energy to refrigerate. The economic costs of climate change impacts have been investigated in Burke et al. (2015), which indicates that almost every country in Africa is vulnerable to increasing temperatures causing a reduction in gross domestic product (GDP). Northern Africa is vulnerable to urban heat stress amplification, where similar weather conditions when combined with the urban heat island leads to significant heat stress. In future climates, this vulnerability is expected to worsen, leading to higher levels of heat stress (Fischer et al. 2012). Heat stress incidence is expected to increase with climate change (Zhao et al. 2015); in tropical regions, this will reduce industrial activity as workplaces become unsuitable. The lost working time will lead to reduced economic productivity. This is of particular importance in the tropics which makes up a large portion of the developing world (Lundgren et al. 2013). Large-scale heatwaves can cause fatalities in Western European nations; countries with fewer resources need to plan ahead to cope with heatwaves (Mitchell et al. 2018). Within Africa the Great Lakes region will experience an increase in heat stress as a result of climate change. Within this region Burundi, the Democratic Republic of the Congo, Uganda and Mozambique are most vulnerable to heat stress (Asefi-Najafabady et al. 2018).

The urban fraction of the total global population is predicted to increase into the twentyfirst century. The urban heat island effect is expected to exacerbate the effects of increasing temperatures increasing the frequency of heat stress (Fischer et al. 2012). The primary response to heat stress is the use of space cooling devices such as fans and air conditioning units. Both are heavily reliant on electricity, and therefore with an increase in potential heat stress, there is likely to be an increase in demand for electricity.

Heatwaves are common in Sahelian Africa, and up to a third of the year is susceptible to temperatures that are highly hazardous to health (Barbier et al. 2018). Globally increasing temperatures as a result of climate change are expected to increase demand for energy to cool residential and commercial properties (Davis and Gertler 2015). In a high emissions scenario, Africa is projected to suffer significant heatwaves (Mora et al. 2017). As the developing world continues to develop, there is expected to be an increase in energy demand for both industrial and residential uses (Medlock and Soligo 2001). In the period 2000-2011, the global residential energy demand increased by $14 \%$, and this increase was primarily driven by urbanisation, population growth and economic growth (Nejat et al. 2015). The 
increase in residential energy demand is largely a result of demand in Asia for air conditioning. There is a similar signal in Africa, however, it is smaller as Africa is projected to be poorer and therefore unable to afford air conditioning (Isaac and van Vuuren 2009). Energy consumption is expected to increase with the intensity of climate change and more intense warming levels lead to higher demand. Global energy demand will increase by $17 \%$ in a high emissions scenario which is driven by tropical changes of $32 \%$ in contrast to 7 and $18 \%$ for a less intense scenario (De Cian and Sue Wing 2017). Climate change is also projected to impact several parts of the energy supply system, and it is vital to understand the potential for compound impacts, particularly in regions of higher vulnerability (Cronin et al. 2018); therefore, improved demand studies focused on health outcomes are valuable.

While reductions in heating energy demand may partially balance out the increases in cooling energy demand, especially at the global scale, the two are not directly equivalent in the energy system, as heating services are largely provided by a variety of different fuels and cooling by electricity (Isaac and van Vuuren 2009). As these increased electricity demands could necessitate increases in generation and transmission capacity, mitigating heat stress with increased space cooling could thus have significant impacts on regional energy systems. These impacts include but are not limited to investment requirements, operating costs, energy prices and thus the wider economy.

Previous studies have examined the impacts of climate change on heating and cooling demands using degree days with set target temperatures and project significant impacts at the regional scale (Isaac and van Vuuren 2009; Labriet et al. 2015). To the authors' knowledge, no studies have so far examined the costs of mitigating heat stress through increased space cooling specifically. This study was conducted as part of the multinational high-end climate impacts and extremes (HELIX) project and is part of a specific focus on Africa. It addresses the research gap explained above by projecting heat stress across Africa on a gridded basis with a climate model ensemble, then uses a least-cost energy system optimisation model to project the change in energy demand for space cooling and the associated costs of mitigating heat stress. Policymakers and energy system planners at national and regional levels should consider the results, to feed into the consideration of climate change mitigation and adaptation strategies.

\section{Input data and model}

The inputs for the analysis are the bias-corrected versions of data produced as part of the Coordinated Regional Climate Downscaling Experiment (CORDEX) Africa project (Nikulin et al. 2012). The CORDEX simulations were developed by driving regional climate models (RCMs) with data from general circulation models (GCMs) used during the CMIP5 project (Taylor et al. 2011). The bias correction was performed as part of the HELIX project with a multisegment statistical bias correction method (Grillakis et al. 2013; Papadimitriou et al. 2015).

The input data used were eleven actualisations of CORDEX-Africa with a temporal resolution of 1 day. In line with the HELIX focus on high-end climate change scenarios, for a model to be used in the analysis, it was required that the GCM reach a global average temperature change of $+4{ }^{\circ} \mathrm{C}$ for 30 years; six of the climate models which were used to drive four regional models over Africa met this criteria. Supplementary Information (SI) Table 1 shows the combinations of GCMs and RCMs used in this study.

The baseline data time period was 1986-2005 which corresponds to the final 20 years of the CMIP5 historic record. The CMIP5 outputs from this time period values were used 
as inputs for the CORDEX-Africa project. By requiring the temperatures reach $+4{ }^{\circ} \mathrm{C}$, the future simulations were all from RCP8.5 which is a high emissions scenario (for details on RCPs see Meinshausen et al. (2011)). The mean of the ensemble of future climates reaches +2 and $+4{ }^{\circ} \mathrm{C}$ during the 30 -year periods centred on 2035 and 2076 respectively. The +2 and $+4{ }^{\circ} \mathrm{C}$ time slices correspond to the specific warming levels (SWL) where the climate is +2 and $+4{ }^{\circ} \mathrm{C}$ warmer than the pre-industrial control. SI Table 2 shows the time slices for the GCM results used for analysis. Due to the warming between the pre-industrial period (1870-1899) and the historic period (1986-2005) of $0.7^{\circ} \mathrm{C}$, the +2 and $+4{ }^{\circ} \mathrm{C}$ warming levels are equivalent to +1.3 and $+3.3{ }^{\circ} \mathrm{C}$ when compared with the 1986-2005 baseline period.

The Shared Socioeconomic Pathway SSP3 was selected for this analysis, as it is consistent with a future of continued high GHG emissions and high levels of climate change (Riahi et al. 2017). This scenario corresponds to a world where policies allow the use of high emission energy sources, and there is little technological development in the energy sector. Furthermore, the focus is on regional rather than global trade and competition, and thus economic interaction between Africa and other regions is minimal. Population data for SSP3 were downscaled to a 0.5-degree grid by Murakami and Yamagata (2016), and the outputs were used to estimate the number of people affected by heat stress. Country-level GDP data was obtained from the IIASA SSP database (O`Neill et al. 2012) and used as a driver for the energy system demand projections. The SSP3 OECD GDP projections were used in this study (Jones and O'Neill 2016).

TIAM-UCL is a technology-rich global optimisation model, which derives the leastcost future energy system within given technological, economic and policy constraints. It models the flows of energy carriers from primary resources to final service demands via stages of extraction, transformation and transportation. The model is calibrated with data describing the global energy system for the base year 2005, taken from the IEA World Energy Balances. The model uses projections of data-including availabilities and costs of primary resources and technologies - to design the optimal energy system transformation from 2005 to the end of the modelling period. Details of the input data are provided in the model documentation (Anandarajah et al. 2011). With perfect foresight over the chosen time period, the model selects energy technologies based on their investment and running costs and operational parameters, so as to meet service demands while minimising the total cost of the system. TIAM-UCL is chosen for this study, as it is a partial equilibrium, bottom-up model. These characteristics allow modification of the demand as an exogenous input, while the model has sufficient technological detail to describe the technologies suited to meet that demand. Scenario analysis can be used to test the effects of features such as policies, technology changes, socio-economic pathways or climate change impacts. The world is represented as 16 regions, one of which is Africa (Anandarajah et al. 2011).

\section{Methods}

\subsection{Heat stress indices}

There are multiple heat stress metrics available for analysis (Buzan et al. 2015), two of which have been selected for further analysis: apparent temperature (AT) (Steadman 1984) and humidex (HD) (Masterton and Richardson 1979; Buzan et al. 2015). Both indices are dependant on temperature and vapour pressure, the latter of which is dependent on surface pressure and specific humidity. The derivation of the vapour pressure and the two indices are 
shown in SI Table 3. The heat stress indices are calculated on each grid cell $\left(0.44^{\circ} \times 0.44^{\circ}\right)$ with a temporal resolution of 1 day.

Each of the heat stress indices has different ranges for slight, moderate, strong and extreme stress: these values were specified in Zhao et al. (2015) and are shown in SI Table 4. As discussed in SM DM1 of Zhao et al. (2015), HD is a comfort index which is used for both indoors and outdoors conditions. The AT indoor version is used in this work and the ranges of values span from just above indoor comfort (slight) to the point at which heat stroke can occur (extreme). For each GCM-RCM combination, the number of days with heat stress in each level were calculated and then averaged to produce the ensemble mean.

\subsection{Heat stress-related cooling}

A reduction in ambient temperature reduces the value of the heat stress indices for a given water vapour pressure, and it is therefore possible with sufficient cooling to prevent a heat stress event. It is possible to calculate the difference in temperature between a heat stress day and a no stress day by rearranging the formulae in SI Table 3. The equations are combined with the lowest limit in SI Table 4 ( 28 for AT and 35 for HD) to produce an equation that defines the maximum possible temperature that combined with the fixed vapour pressure would not cause heat stress. The rearranged temperature limit calculations are shown in SI Table 5, where $T_{\text {target }}$ is the target temperature at which any increase would cause heat stress for that value of vapour pressure. The difference between the simulated temperature and the target temperature is the cooling requirement. As part of this initial sensitivity study, the impact of changing temperature on the water vapour capacity of the air parcel has been neglected. This equation is solved for each day of the simulations and the results are summed to find the annual cooling requirement in cooling degree days (CDDs). The cooling required to mitigate heat stress under the baseline and future climate and population are calculated on a gridded basis across Africa by multiplying the corresponding gridded CDD results by the gridded SSP3 population data.

\subsection{Energy demand for high stress mitigation}

Energy service demands are an exogenous input to the TIAM-UCL model over the modelled period. The 2005 energy demands for space cooling in the Africa commercial and residential sectors is 21.8 and 27.8 PJ respectively, representing some use of fans and air conditioning units. These figures are derived from the IEA World Energy Balances and expert judgement (Anandarajah et al. 2011). Subsequent energy service demands are calculated for each modelled time slice $(t)$ based on the previous timestep value $(t-1)$ and growth in various socio-economic drivers modulated by corresponding elasticity parameters. These elasticities represent how closely the demands are coupled to the drivers and vary over the modelled time horizon. Their values are taken from the ETSAP-TIAM model and are calibrated across the energy demands in the model to represent saturation of energy service use and convergence between developing and industrialized countries. The energy demands for residential cooling (RC) and commercial cooling (CC) are calculated with Eqs. 1 and 2, where $N$ is the number of households, GDPH is the GDP per household, $k$ is an elasticity parameter and PSER is the service industry activity (in trillion USD). These drivers are derived from the country-level population and GDP projections for SSP3, summed over Africa.

$$
\begin{gathered}
\mathrm{RCD}_{t}=\mathrm{RCD}_{t-1} \times N \times \mathrm{GDPH}^{k} \\
\mathrm{CCD}_{t}=\mathrm{CCD}_{t-1} \times \mathrm{PSER}^{k}
\end{gathered}
$$


For this analysis, it is assumed that all space cooling services in the model are used to mitigate heat stress and so the total cooling demand is the sum of the cooling required to mitigate each heat stress level. As described by Brown et al. (2016), the relationship between temperature and cooling demand may be represented by different functions depending on factors including building properties, diffusion of cooling technologies and cultural preferences. Following the method of Labriet et al. (2015), this study assumes that the usage of cooling appliances changes but the diffusion of appliances does not change as a response to climate change. Based on this, the cooling demands are assumed to scale proportionally with the change in cooling degree days.

Given these assumptions, to simulate the impact of heat stress mitigation on energy demand, the CDDs required to mitigate heat stress are calculated by summing the population-weighted apparent temperature CDD results (Section 3.2) over Africa. These are used to derive the scaling factor A (Eq. 3), which is the ratio of the population-weighted cooling degree days required to prevent all heat stress at the future and historic warming levels: $\mathrm{CDD}_{\text {future }}$ and $\mathrm{CDD}_{\text {historic }}$.

$$
A=\frac{\mathrm{CDD}_{\text {future }}}{\mathrm{CDD}_{\text {historic }}}
$$

\subsection{Country-level cooling demands}

The cooling demand required to mitigate heat stress for the whole of Africa is downscaled to give the cooling demand for each country. This is done by apportioning the continental increase in energy demand between the countries according to the fraction of additional population-weighted CDDs occurring in each country. See Eqs. 4 and 5, where $\Delta$ CDclim $_{i, t}$ is the additional cooling demand for country $i$ at time $t$ due to climate change, $\Delta \operatorname{CDclim}_{A, t}$ is the additional cooling demand for Africa at time $t$ due to climate change. $\triangle \operatorname{PopCDD}_{i, t-T}$ is the change in population-weighted CDDs for country $i$ between times $T$ (2005) and $t$ (2035 or 2076) and $\triangle \operatorname{PopCDD}_{A, t-T}$ is the change in population-weighted CDDs for Africa between times $T$ (2005) and $t$ (2035 or 2076). $\mathrm{CD}_{A, t, \mathrm{CC}}$ and $\mathrm{CD}_{A, t, \text { noCC }}$ are the cooling demands for Africa at time $t$ with and without climate change respectively. As an initial high-level indication of the challenge these additional electricity demands present to each country, the results are also presented per unit of GDP per capita. A schematic of the approach linking TIAM-UCL to the heat stress data is shown in SI Fig. 1.

$$
\begin{gathered}
\Delta \operatorname{CDclim}_{i, t}=\Delta \operatorname{CDclim}_{A, t} \times \frac{\Delta \operatorname{PopCDD}_{i, t-T}}{\Delta \operatorname{PopCDD}_{A, t-T}} \\
\Delta \mathrm{CDclim}_{A, t}=\mathrm{CD}_{A, t, \mathrm{CC}}-\mathrm{CD}_{A, t, \mathrm{noCC}}
\end{gathered}
$$

\subsection{Costs of heat stress mitigation}

To calculate the costs of transforming the energy system to meet these increased demands, the TIAM-UCL model is run for the period 2005-2100, the extended time horizon reflecting the fact that policymakers and industry agents make decisions to prepare for, and which affect, the years and decades to come. In TIAM-UCL, the Africa region is split into rural (1) and urban (2) sub-regions for which the residential demand drivers and elasticities are defined separately. This represents the significant differences in access to energy supply and service technologies between the urban and rural populations. The commercial demand is not split into urban and rural regions. The model is run with two scenarios: the base case and the climate change case. In the base case, the cooling demands are only functions of 
the growth in the socio-economic drivers, as described above (Eqs. 1 and 2) and are not affected by any change from the present climate condition. In the climate change case, they are also scaled by the factor A (Eq. 3) to account for heat stress under a warmer climate in the future. Thus, the cooling demands in the two scenarios are equal for the base year 2005, then diverge through future years.

\section{Results}

\subsection{Heat stress results}

Figure 1 shows the impact of a two- and four-degree warming on apparent temperature heat stress occurrence across Africa; the humidex results are shown in SI Figure 2. For both indices, the same pattern emerges: either the number of slight heat stress events increases, indicating that regions previously unaffected are now vulnerable, or where the number of slight events decreases the number of moderate, and in the case of apparent temperature strong, heat stress events increases. When global temperatures are $4{ }^{\circ} \mathrm{C}$ above the historic average (Fig. 1, SI Figure 2), the heat stress changes follow a similar geographic pattern to $\mathrm{a}+2{ }^{\circ} \mathrm{C}$ change but with a higher intensity. This higher intensity is also accompanied by an increase in the number of strong heat stress events using the humidex index.

The standard deviation of the number of days in each heat stress level were calculated and the difference between the historic and future standard deviations are shown in SI Figures 3 and 4. The largest increase in variability is around central Africa where the number of heat stress days moving from slight to moderate varies more across the GCM-RCM pairings.

The number of grid cells exposed to extreme heat stress increases significantly when temperatures are $4{ }^{\circ} \mathrm{C}$ above the pre-industrial limits. In general, the distribution of heat stress events increases in severity with climate change. The increase in moderate and stronger events affects highly populated coastlines and West African Sahelian nations. The same response is found in Central Africa over much of the Central African Republic and the Democratic Republic of the Congo. The equatorial and tropical regions show higher instances of heat stress with changes in strong heat stress events almost exclusively in the Northern Hemisphere. The highly populated West African region experiences the largest changes in moderate and strong heat stress events.

\subsection{Increase in cooling demand}

The difference in the cooling requirement to prevent heat stress between the historic and future simulations are shown in Fig. 2. The variation in results from the 11 model combinations was examined. The standard deviation in the cooling required to prevent heat stress is shown in SI Figure 5. The spread in the cooling required is greatest in central Africa; this is the result of the variability in the monsoon systems in the input meteorology. The cooling demands taking into account future climate change are calculated for the time slices at +2 and $+4{ }^{\circ} \mathrm{C}$ and are linearly interpolated to define the demand pathways. SI Figure 6 shows the cooling demands for the base and climate change cases. In 2005, space cooling accounts for $0.4 \%$ of the total final energy demand in Africa. In the base case, this drops to $0.2 \%$ by 2100 but in the climate change case space cooling rises to account for $1.2 \%$ of the total final energy demand by 2100 . 

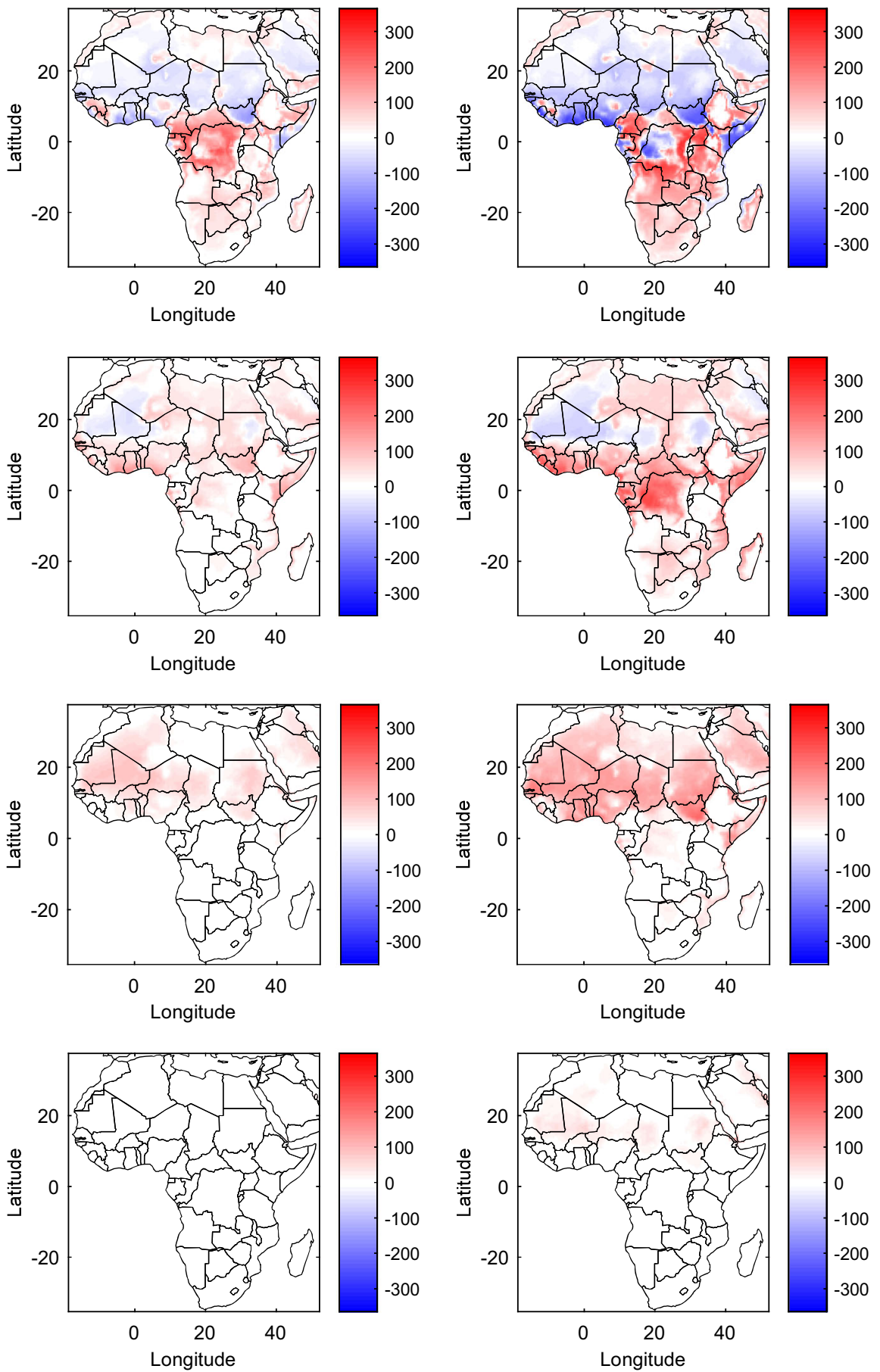

Fig. 1 Difference in apparent temperature events per year between the $+2{ }^{\circ} \mathrm{C}$ (left) and $+4{ }^{\circ} \mathrm{C}$ (right) and baseline time slices for slight (first row), moderate (second row), strong (third row) and extreme (fourth row) levels 

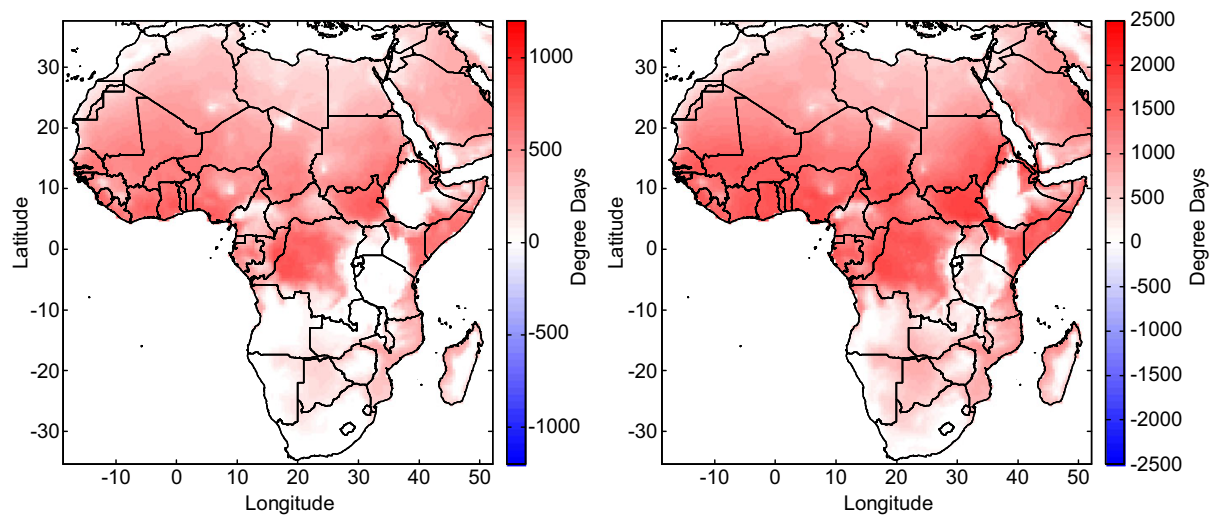

Fig. 2 Difference in cooling degree days required to prevent all apparent temperature heat stress between $+2{ }^{\circ} \mathrm{C}$ (left), $+4{ }^{\circ} \mathrm{C}$ (right) and baseline conditions

\subsection{Country-level demand}

Figure 3 shows the additional cooling demand that would occur in each country under +2 and $+4{ }^{\circ} \mathrm{C}$ warming. Due to the significant increase in heat stress and high population density, the greatest increases in cooling demand occurs in Nigeria, followed by the Democratic Republic of Congo, Egypt and Sudan. However, supplying these additional electricity demands will present different challenges to each country, depending on factors such as the

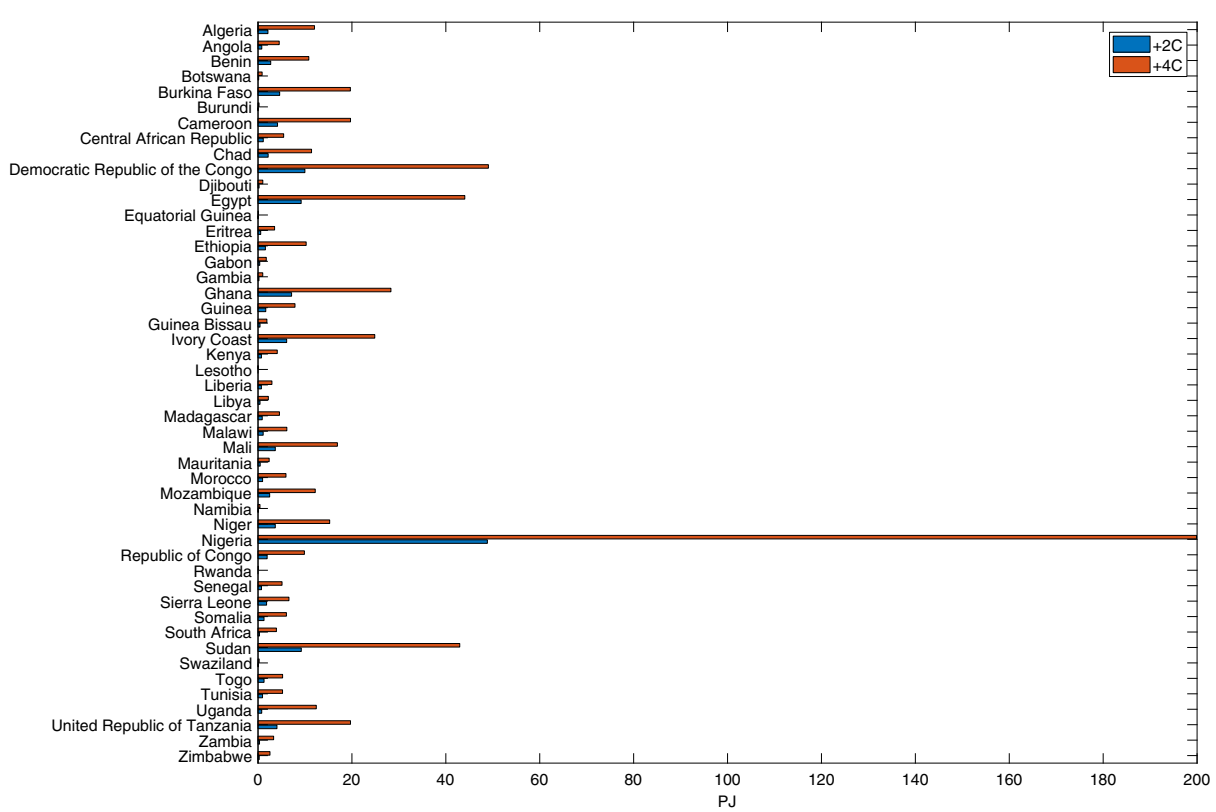

Fig. 3 Country-level additional cooling demand due to heat stress mitigation under RCP8.5 for two timeslices 
existing energy system, the country's wealth, and the style of governance and system planning. As an initial high-level indicator of this, Fig. 4 shows the additional cooling demands per unit of GDP per capita. This suggests the additional cooling demand will present the greatest challenges to Somalia, Guinea Bissau, Djibouti and Central African Republic, particularly at the lower warming level $\left(2{ }^{\circ} \mathrm{C}\right.$ in 2035), as this occurs before the large increases in GDP and population.

\subsection{Impact of increased cooling energy demand}

TIAM-UCL results for the base case and the case with heat stress cooling demand (climate change case) are compared. SI Figure 7 shows the impact of the increased residential and commercial cooling demand on the final energy consumption of all the economic sectors. The changes in the residential and commercial sectors induce changes in the generation technology and fuel mix in other sectors; for example, final energy consumption in the transport sector decreases slightly in the middle of the century when gas is partially replaced with electricity, and energy consumption in the upstream sector decreases around 2060 and 2080 as the use of electricity and heat respectively are reduced. The total energy consumption of the Africa region is increased by $0.1 \%$ in 2035 and $0.3 \%$ in 2076 due to the additional cooling to mitigate heat stress.

The increased cooling demands in the climate change case do not affect the technologies selected by TIAM-UCL to fulfil these end demands. From 2020 onwards in both scenarios, commercial cooling is entirely provided by rooftop chiller units and residential cooling is entirely provided by room air conditioning units.

SI Figure 8 shows the mix of electricity generation technologies in the base case. The share of renewable energy sources - solar PV and hydroelectricity - grows rapidly from the

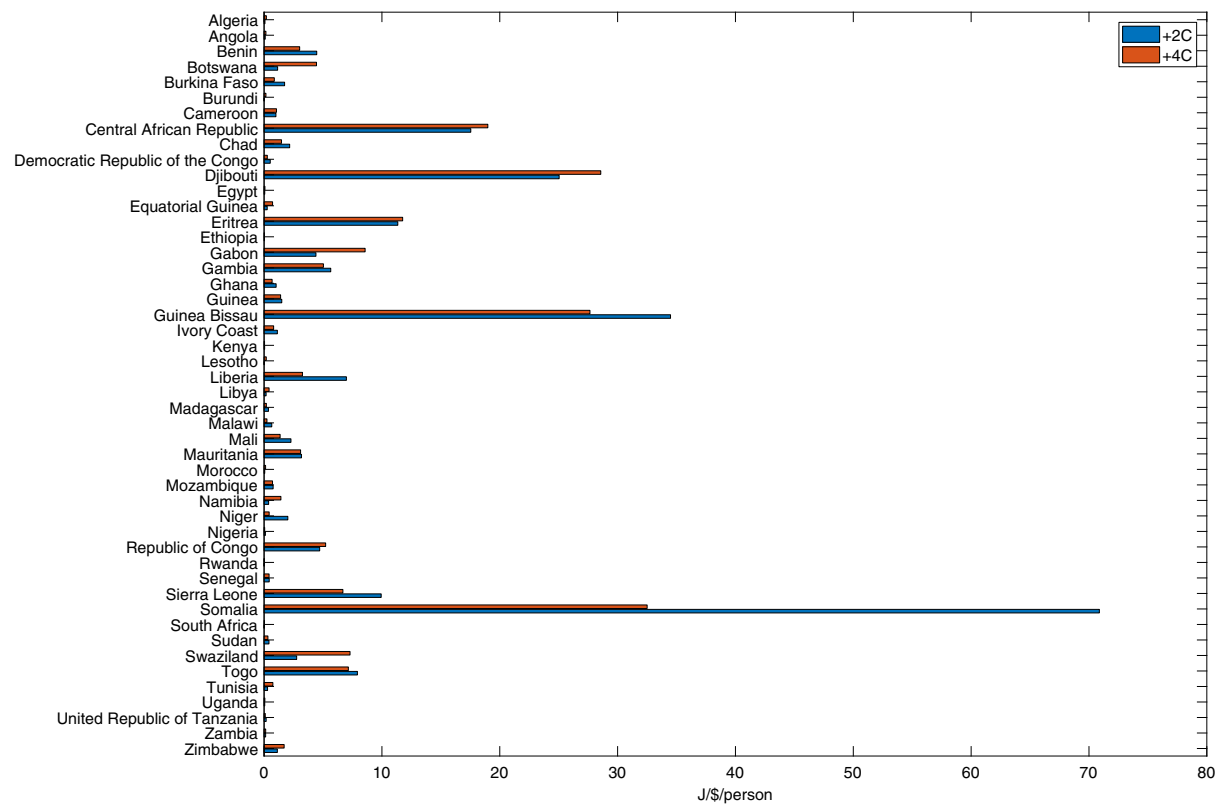

Fig. 4 Additional energy demand per unit of GDP per capita under RCP8.5 for two timeslices 
middle of the century. To provide the additional electricity required in the climate change case, approximately $3 \%$ additional generation is required from 2040 onwards. Of this additional generation, solar PV provides an increasing share rising from 5\% in 2045 to $15 \%$ in 2070. This mainly replaces coal in the technology mix, while the share of natural gas remains approximately constant around $3 \%$.

TIAM-UCL models the transformation of the energy system through the modelling period. The total cost of the regional energy system over that period is composed of expenditures (such as capital required for building and decommissioning technologies, operations and maintenance, fuel costs, commodity imports, commodity delivery and taxes) and revenues (from commodity exports, subsidies and the salvage values of decommissioned technologies). In reality, these costs are paid and recouped by a number of different parties over various timescales. As several of these finance streams occur earlier or later than the energy generation which they facilitate, TIAM-UCL includes mechanisms to annualise them over the period of generation (Loulou et al. 2016). As the energy supply in a given year is made possible by the construction and operation of supply technologies in previous years, the energy system cost (cost (ES)) relevant for this analysis is defined as the sum of the annual investment and operations costs from the model base year up to the year in question. These cumulative costs are all reported in year 2005 US \$ and are undiscounted.

Table 1 shows the Africa cumulative energy system costs for the base case and climate change case. Due to the increased cooling demand required to mitigate heat stress resulting from the $+2{ }^{\circ} \mathrm{C}$ global average temperature rise, the integrated energy system cost from 2005 to 2035 increases by $0.26 \%$, which is equivalent to approximately $\$ 51.3$ billion. With $+4{ }^{\circ} \mathrm{C}$ global average temperature rise, the integrated energy system cost from 2005 to 2076 increases by $0.60 \%$, which is equivalent to approximately $\$ 486.5$ billion.

\section{Discussion}

Across the entire African continent, there is a projected increase in the total number of heat stress events. In regions where the number of slight or moderate heat stress events falls, there is an increase in the number of more severe events. The increase in overall intensity of heat stress happens in highly populated regions such as the Nigerian coast, the Great Lakes and along several major rivers including the Nile, Volta, Niger and Zambezi. Heat stress has a more profound effect on the vulnerable members of society such as those living alone, the young or the elderly (Uejio et al. 2011) or those will chronic health problems such as heart conditions or mental health issues (Zhang et al. 2017); therefore, expected increases in heat stress should be noted by social and health services in these regions. The cooling demand is relatively consistent across the 11 GCM-RCM combinations; however, as the GCMs attain the SWLs at different times, the variability in population is large.

Table 1 Energy system cost changes associated with preventing heat stress between the historic period and the +2 and $+4{ }^{\circ} \mathrm{C}$ timeslices

\begin{tabular}{lll}
\hline Period & $2005-2035$ & $2005-2076$ \\
\hline Temperature increase & $+2{ }^{\circ} \mathrm{C}$ & $+4{ }^{\circ} \mathrm{C}$ \\
Cumulative additional cost (billion USD) & $\$ 51.327$ & $\$ 486.526$ \\
Energy system cost rise over base case & $0.26 \%$ & $0.60 \%$ \\
Cost rise as fraction of GDP & $0.03 \%$ & $0.06 \%$ \\
\hline
\end{tabular}


The apparent temperature heat stress results were used to scale the cooling service energy demand for the Africa region in the TIAM-UCL model. Country-level analysis showed the greatest demand increases in the latter part of this century in countries with the highest warming levels and population density. However, it is expected that the greatest challenges will be presented earlier in the century to countries where the increase in heat stress is high relative to the level of economic development.

Meeting the additional energy demand had the effect of increasing the energy system cost over the $2005-2076$ period by $0.6 \%$, which corresponds to $0.06 \%$ of the cumulative GDP for Africa over the same period. The additional yearly cost increases with time (as global warming increases). Although the population of Africa is projected to increase with time, the cost per person also increases. Over the 10-year periods centred on $2035\left(+2{ }^{\circ} \mathrm{C}\right)$ and $2076\left(+4{ }^{\circ} \mathrm{C}\right)$, the additional cost required to mitigate heat stress corresponds to an average additional cost of $\$ 2.29$ and $\$ 5.52$ per person per year respectively. To put this in context, between 2000 and 2013 investment in the power sector in Africa accounted for on average \$12 billion per year (International Energy Agency 2014), which is equivalent to approximately $\$ 12$ per person per year.

The estimated cumulative cost of $\$ 51.3$ billion to prevent heat stress in Africa between 2005 and 2035 can be compared with the total infrastructure costs estimated in Parry et al. (2009), where the removal of infrastructure deficit and adapting infrastructure cost is estimated to be between $\$ 64.7$ billion and $\$ 73.9$ billion. The results in Parry et al. (2009) employed the A1B emissions scenarios from IPCC Assessment Report 4, which is a moderate emissions scenario and analogous to RCP4.5. This is a lower emissions scenario than used in our study; however, the differences are not large by 2030. Therefore, the results herein, which focus solely on the effect of increasing cooling demand on the energy system, indicate that the total costs in Parry et al. (2009) may be underestimated.

The input data used in this study were based on bias corrected CORDEX-Africa simulations that were driven by RCP 8.5 simulations from CMIP5. RCP8.5 is a high emission scenario with limited adaptation and mitigation of climate change (Meinshausen et al. 2011). In the cases of RCP2.6, RCP4.5 or RCP6.0, the expected temperature change is lower; this would results in a lower value for the heat stress metric and fewer events that exceed the predefined limits. A lower number of heat stress events will result in lower costs for adapting the energy system to provide sufficient electricity to prevent heat stress. The highly non-linear relationship between climate scenario and costs however make it impossible to provide a numeric value for the energy system costs in lower emission scenarios.

This study has some key limitations, which should be addressed in further work. First, in the heat stress calculation, the impact of changing temperature on the water capacity of the air parcel has been neglected. In the economic modelling, the climate change effect of heat stress is applied to the Africa region and cooling demand only. Clearly, climate change will also affect other regions and elements of the energy system, such as heating demand and renewable resources, whose combined impacts could affect the technology choices made by TIAM-UCL in individual regions, commodity trading between regions, and thus the regional and global mitigation costs. The urban heat island (UHI) effect can raise the temperature of cities by several degrees in comparison with surrounding rural areas (Tran et al. 2006; Oke 1982).

The analysis conducted in TIAM-UCL is performed using the multi-model ensemble mean levels of cooling required to prevent heat stress. The range of values used to generate this ensemble mean is dependent on the climate sensitivity of the GCM as this determines when the SWLs are reached. The timing of reaching the SWLs contributes to the total CDD 
requirement primarily as a result of population change with lower climate sensitivity leading to a later SWL and therefore a higher population. As the feedbacks within TIAM-UCL are non-linear, further research into the range of cooling requirements is an area of future study.

The CMIP5 GCMs and CORDEX-Africa RCMs do not simulate the UHI effect; therefore, it is not possible to analyse it directly. Analysis of the UHI is often performed using high-resolution models or nested domains such as in Vahmani et al. (2016). With the increasing urbanisation of Africa (Cohen 2006; Parnell and Walawege 2011), the fraction of the population exposed to the urban heat island effect will increase. Therefore, the actual cooling demand and the associated costs are likely to be higher than the results presented here. This analysis should therefore be considered a sensitivity study and a demonstration of the use of technical (rather than economic) climate change feedback in the TIAM-UCL model to evaluate adaptation costs. Further work should focus on including further impacts of climate change on energy demand and supply in the TIAM-UCL model and adopting a global approach. The country-level analysis of heat stress and cooling demand also suggest energy system modelling and infrastructure planning for several countries should account for climate change impacts on demand.

\section{Conclusion}

Heat stress is an existing problem that affects many countries in Africa, with the highest intensities present in the tropics. Exposure to heat stress is projected to increase into the twenty-first century with increasing frequency of high-intensity events. In the highly populated Sahelian region, strong and extreme events are projected to become much more regular. The energy system will face extra demand as populations increase and urbanise. The combination of extra heat stress and larger populations mean that the energy system will need significant investment to prevent electricity grid failures.

The results herein indicate that the Democratic Republic of the Congo, Egypt, Nigeria and Sudan are projected to have the highest costs incurred in adapting the energy system to prevent heat stress. The financial impacts are different when spread over the populations, Nigeria is relatively rich and highly populous and therefore faces a small individual cost. In contrast, the nations of the Central African Republic, Djibouti, Guinea Bissau and Somalia have the highest cost per unit of GDP per capita.

The energy system however cannot be treated in isolation and further research should be conducted at a national or sub-national scale to asses the impact of heat stress. Heat stress is associated with heatwaves; there is potential that there will be competition between electricity generation, drinking water demand and irrigation for limited water.

With the signing of the Paris accord (United Nations 2015), the global community agreed to work to prevent the catastrophic climate changes that are projected in RCP8.5. However, strong action to reduce carbon dioxide emissions is necessary to reach the agreed goals. This study indicates that under a high climate change scenario, infrastructure costs for adaptation may be larger than previous estimated. This should be considered by energy system planners and policymakers when balancing mitigation and adaptation options. With the long lead time of energy systems, often measured in decades, decision-makers will be faced with choosing between increasing capacity to prevent potential heat stress or being unable to provide energy when the need is critical.

Acknowledgements The authors would also like to thank the reviewers for their insightful and constructive comments. 
Funding information The research leading to these results has received funding from the European Union Seventh Framework Programme FP7/2007-2013 under grant agreement ${ }^{\circ} 603864$ (HELIX: High-End cLimate Impacts and eXtremes; http://www.helixclimate.eu). This research was made possible by support from the EPSRC as a Standard Research Studentship (DTP), grant no. EP/M507970/1. Dr Ben Parkes is the recipient of the Ekpe Research Impacts Fellowship at the School of Mechanical, Aerospace and Civil Engineering at The University of Manchester.

Open Access This article is distributed under the terms of the Creative Commons Attribution 4.0 International License (http://creativecommons.org/licenses/by/4.0/), which permits unrestricted use, distribution, and reproduction in any medium, provided you give appropriate credit to the original author(s) and the source, provide a link to the Creative Commons license, and indicate if changes were made.

\section{References}

Anandarajah G, Pye S, Usher W, Kesicki F, Mcglade C (2011) TIAM-UCL global model documentation. Tech. rep., University College London

Asefi-Najafabady S, Vandecar KL, Seimon A, Lawrence P, Lawrence D (2018) Climate change, population, and poverty: vulnerability and exposure to heat stress in countries bordering the Great Lakes of Africa. Clim Chang 148(4):561-573. https://doi.org/10.1007/s10584-018-2211-5

Barbier J, Guichard F, Bouniol D, Couvreux F, Roehrig R (2018) Detection of intraseasonal large-scale heat waves: characteristics and historical trends during the Sahelian spring. J Clim 31(1):61-80. https://doi.org/10.1175/JCLI-D-17-0244.1

Brown MA, Cox M, Staver B, Baer P (2016) Modeling climate-driven changes in U.S. buildings energy demand. Clim Chang 134(1):29-44. https://doi.org/10.1007/s10584-015-1527-7

Burke M, Hsiang SM, Miguel E (2015) Global non-linear effect of temperature on economic production. Nature 527(7577):235-239

Buzan JR, Oleson K, Huber M (2015) Implementation and comparison of a suite of heat stress metrics within the Community Land Model version 4.5. Geosci Model Dev 8(2):151-170. https://doi.org/10.5194/gmd-8-151-2015

Cohen B (2006) Urbanization in developing countries: current trends, future projections, and key challenges for sustainability. Technol Soc 28(1):63-80. https://doi.org/10.1016/j.techsoc.2005.10.005. http://www. sciencedirect.com/science/article/pii/S0160791X05000588, sustainable Cities

Cronin J, Anandarajah G, Dessens O (2018) Climate change impacts on the energy system: a review of trends and gaps. Climatic Change. https://doi.org/10.1007/s10584-018-2265-4

Davis LW, Gertler PJ (2015) Contribution of air conditioning adoption to future energy use under global warming. Proc Natl Acad Sci 112(19):5962-5967. https://doi.org/10.1073/pnas.1423558112. http:// www.pnas.org/content/112/19/5962

De Cian E, Sue Wing I (2017) Global energy consumption in a warming climate. Environmental and Resource Economics. https://doi.org/10.1007/s10640-017-0198-4

Diffenbaugh NS, Pal JS, Giorgi F, Gao X (2007) Heat stress intensification in the Mediterranean climate change hotspot. Geophys Res Lett 34(11):n/a-n/a. https://doi.org/10.1029/2007GL030000, 111706

Dunne JP, Stouffer RJ, John JG (2013) Reductions in labour capacity from heat stress under climate warming. Nature Clim Change 3(6):563-566

Field CB, Barros VR, Mach KJ, Mastrandrea MD, Mv Aalst, Adger WN, Arent DJ, Barnett J, Betts R, Bilir TE, Birkmann J, Carmin J, Chadee DD, Challinor AJ, Chatterjee M, Cramer W, Davidson DJ, Estrada YO, Gattuso JP, Hijioka Y, Hoegh-Guldberg O, Huang HQ, Insarov GE, Jones RN, Kovats RS, Lankao PR, Larsen JN, Losada IJ, Marengo JA, McLean RF, Mearns LO, Mechler R, Morton JF, Niang I, Oki T, Olwoch JM, Opondo M, Poloczanska ES, Pörtner HO, Redsteer MH, Reisinger A, Revi A, Schmidt DN, Shaw MR, Solecki W, Stone DA, Stone JMR, Strzepek KM, Suarez AG, Tschakert P, Valentini R, Vicuña S, Villamizar A, Vincent KE, Warren R, White LL, Wilbanks TJ, Wong PP, Yohe GW (2014) Technical summary. In: Field CB, Barros VR, Dokken DJ, Mach KJ, Mastrandrea MD, Bilir TE, Chatterjee M, Ebi KL, Estrada YO, Genova RC, Girma B, Kissel ES, Levy AN, MacCracken S, Mastrandrea PR, White LL (eds) Climate change 2014: impacts, adaptation, and vulnerability. Part A: Global and Sectoral Aspects. Contribution of Working Group II to the Fifth Assessment Report of the Intergovernmental Panel on Climate Change. Cambridge University Press, Cambridge, pp 35-94

Fischer EM, Oleson KW, Lawrence DM (2012) Contrasting urban and rural heat stress responses to climate change. Geophys Res Lett 39(3):n/a-n/a. https://doi.org/10.1029/2011GL050576, 103705 
Grillakis MG, Koutroulis AG, Tsanis IK (2013) Multisegment statistical bias correction of daily GCM precipitation output. J Geophys Res Atmos 118(8):3150-3162. https://doi.org/10.1002/jgrd.50323

International Energy Agency (2014) World energy investment outlook. http://www.iea.org/publications/ freepublications/publication/WEIO2014.pdf

Isaac M, van Vuuren DP (2009) Modeling global residential sector energy demand for heating and air conditioning in the context of climate change. Energy Policy 37(2):507-521. https://doi.org/10.1016/j.enpol. 2008.09.051

Jones B, O'Neill BC (2016) Spatially explicit global population scenarios consistent with the shared socioeconomic pathways. Environ Res Lett 11(8):084,003. http://stacks.iop.org/1748-9326/11/i=8/a=084003

Kjellstrom T, Holmer I, Lemke B (2009) Workplace heat stress, health and productivity - an increasing challenge for low and middle-income countries during climate change. Glob Health Action 2(1):2047. https://doi.org/10.3402/gha.v2i0.2047

Labriet M, Joshi SR, Vielle M, Holden PB, Edwards NR, Kanudia A, Loulou R, Babonneau F (2015) Worldwide impacts of climate change on energy for heating and cooling. Mitig Adapt Strateg Glob Chang 20(7):1111-1136. https://doi.org/10.1007/s11027-013-9522-7

Loulou R, Goldstein G, Kamudia A, Lettila A, Remme U (2016) Documentation for the TIMES Model Part I, ETSAP https://iea-ieaetsap.org/docs/Documentation_for_the_TIMES_Model-Part-I_July-2016.pdf

Lundgren K, Kuklane K, Chuansi GAO, Holmér I (2013) Effects of heat stress on working populations when facing climate change. Ind Health 51(1):3-15. https://doi.org/10.2486/indhealth.2012-0089

Masterton J, Richardson F (1979) Humidex: a method of quantifying human discomfort due to excessive heat and humidity. $28 \mathrm{~cm}$. cli,1, Ministere de l'Environnement

Medlock K, Soligo R (2001) Economic development and end-use energy demand. Energy J 22(Number 2):77-105. https://EconPapers.repec.org/RePEc:aen:journl:2001v22-02-a04

Meinshausen M, Smith S, Calvin K, Daniel J, Kainuma M, Lamarque JF, Matsumoto K, Montzka S, Raper S, Riahi K, Thomson A, Velders G, Vuuren D (2011) The RCP greenhouse gas concentrations and their extensions from 1765 to 2300. Clim Chang 109(1-2):213-241. https://doi.org/10.1007/s10584-0110156-z

Mitchell D, Heaviside C, Schaller N, Allen M, Ebi KL, Fischer EM, Gasparrini A, Harrington L, Kharin V, Shiogama H, Sillmann J, Sippel S, Vardoulakis S (2018) Extreme heat-related mortality avoided under Paris agreement goals. Nat Clim Chang 8(7):551-553. https://doi.org/10.1038/s41558-018-0210-1

Mora C, Dousset B, Caldwell IR, Powell FE, Geronimo RC, Bielecki C, Counsell CWW, Dietrich BS, Johnston ET, Louis LV, Lucas MP, McKenzie MM, Shea AG, Tseng H, Giambelluca TW, Leon LR, Hawkins E, Trauernicht C (2017) Global risk of deadly heat. Nat Clim Chang 7:501. https://doi.org/10.1038/nclimate3322

Murakami D, Yamagata Y (2016) Estimation of gridded population and gdp scenarios with spatially explicit statistical downscaling. arXiv:1610.09041

Nejat P, Jomehzadeh F, Taheri MM, Gohari M, Abd Majid MZ (2015) A global review of energy consumption, $\mathrm{CO} 2$ emissions and policy in the residential sector (with an overview of the top ten $\mathrm{CO} 2$ emitting countries). Renew Sust Energ Rev 43(C):843-862. https://doi.org/10.1016/j.rser.2014.11.09. https://ideas.repec.org/a/eee/rensus/v43y2015icp843-862.html

Nikulin G, Jones C, Giorgi F, Asrar G, Büchner M, Cerezo-Mota R, Christensen OB, Déqué M, Fernandez J, Hänsler A, van Meijgaard E, Samuelsson P, Sylla MB, Sushama L (2012) Precipitation climatology in an ensemble of CORDEX-Africa regional climate simulations. J Climate 25(18):6057-6078. https://doi.org/10.1175/JCLI-D-11-00375.1

Oke TR (1982) The energetic basis of the urban heat island. Q J R Meteorol Soc 108(455):1-24. https://doi.org/10.1002/qj.49710845502

O`Neill BC, Carter TR, Ebi KL, Edmonds J, Hallegatte S, Kemp-Benedict E, Kriegler E, Mearns L, Moss R, Riahi K, van Ruijven B, van Vuuren D (2012) Meeting report of the workshop on the nature and use of new socioeconomic pathways for climate change research, Boulder, CO, November 2-4, 2011. Available at: http://www.isp.ucar.edu/socio-economic-pathways

Papadimitriou LV, Koutroulis AG, Grillakis MG, Tsanis IK (2015) High-end climate change impact on European water availability and stress: exploring the presence of biases. Hydrol Earth Syst Sci Discuss 12(7):7267-7325. https://doi.org/10.5194/hessd-12-7267-2015

Parnell S, Walawege R (2011) Sub-saharan African urbanisation and global environmental change. Glob Environ Chang 21(Supplement 1):S12-S20. https://doi.org/10.1016/j.gloenvcha.2011.09.014, migration and Global Environmental Change - Review of Drivers of Migration

Parry M, Arnell N, Berry P, Dodman D, Fankhauser S, Hope C, Kovats S, Nicholls R, Satterthwaite D, Tiffin R, Wheeler T (2009) Assessing the costs of adaptation to climate change: a review of the UNFCCC and other recent estimates. Tech rep. International Institute for Environment and Development and Grantham Institute for Climate Change, London 
Riahi K, van Vuuren DP, Kriegler E, Edmonds J, O`Neill BC, Fujimori S, Bauer N, Calvin K, Dellink R, Fricko O, Lutz W, Popp A, Cuaresma JC, Samir KC, Leimbach M, Jiang L, Kram T, Rao S, Emmerling J, Ebi K, Hasegawa T, Havlik P, Humpenöder F, Silva LAD, Smith S, Stehfest E, Bosetti V, Eom J, Gernaat D, Masui T, Rogelj J, Strefler J, Drouet L, Krey V, Luderer G, Harmsen M, Takahashi K, Baumstark L, Doelman JC, Kainuma M, Klimont Z, Marangoni G, Lotze-Campen H, Obersteiner M, Tabeau A, Tavoni M (2017) The shared socioeconomic pathways and their energy, land use, and greenhouse gas emissions implications: an overview. Glob Environ Chang 42:153-168. https://doi.org/10.1016/j.gloenvcha.2016.05.009

Steadman RG (1984) A universal scale of apparent temperature. J Climate Appl Meteor 23(12):1674-1687. https://doi.org/10.1175/1520-0450(1984)023<1674:AUSOAT > 2.0.CO;2

Suzuki-Parker A, Kusaka H (2016) Future projections of labor hours based on WBGT for Tokyo and Osaka, Japan, using multi-period ensemble dynamical downscale simulations. Int J Biometeorol 60(2):307-310

Taylor KE, Stouffer RJ, Meehl GA (2011) An overview of CMIP5 and the experiment design. Bull Amer Meteor Soc 93(4):485-498. https://doi.org/10.1175/BAMS-D-11-00094.1

Tran H, Uchihama D, Ochi S, Yasuoka Y (2006) Assessment with satellite data of the urban heat island effects in Asian mega cities. Int J Appl Earth Obs Geoinf 8(1):34-48. https://doi.org/10.1016/j.jag.2005.05.003

Uejio CK, Wilhelmi OV, Golden JS, Mills DM, Gulino SP, Samenow JP (2011) Intra-urban societal vulnerability to extreme heat: the role of heat exposure and the built environment, socioeconomics, and neighborhood stability. Health Place 17(2):498-507. https://doi.org/10.1016/j.healthplace.2010.12.005, geographies of Care

United Nations (2015) Adoption of the Paris agreement. In: 21st Conference of the Parties, Paris, United Nations

Vahmani P, Sun F, Hall A, Ban-Weiss G (2016) Investigating the climate impacts of urbanization and the potential for cool roofs to counter future climate change in Southern California. Environ Res Lett 11(12):124,027. http://stacks.iop.org/1748-9326/11/i=12/a=124027

Zhang Y, Nitschke M, Krackowizer A, Dear K, Pisaniello D, Weinstein P, Tucker G, Shakib S, Bi P (2017) Risk factors for deaths during the 2009 heat wave in Adelaide, Australia: a matched case-control study. Int J Biometeorol 61(1):35-47. https://doi.org/10.1007/s00484-016-1189-9

Zhao Y, Ducharne A, Sultan B, Braconnot P, Vautard R (2015) Estimating heat stress from climate-based indicators: present-day biases and future spreads in the CMIP5 global climate model ensemble. Environ Res Lett 10(8):084-013

Publisher's note Springer Nature remains neutral with regard to jurisdictional claims in published maps and institutional affiliations. 